\title{
EVALUATION OF EFICACY OF ROTAHALER WITH FLUTICASONE AND SALMETEROL MEDICATION IN ASTHMATIC CHILDREN
}

\author{
Suddapalli Sivaram Prasad ${ }^{1}$
}

${ }^{1}$ Associate Professor, Department of Pediatrics, Katuri Medical College \& Hospital, Guntur.

ABSTRACT: AIM: To evaluate efficacy of Rotahaler with fluticasone and salmeterol medication in childhood bronchial asthma.

MATERIALS AND METHODS: A prospective study was planned with 30 patients of both sexes in the age group of 5-12 years, who reported to asthma clinic and fulfilled inclusion and exclusion criteria were included in the study after parental consent. All patients included in the trail were initially entered in to run-in period of 2 weeks, during which a record was maintained of their clinical parameters and allowed to take their prescribed medication. At the end of run-in period the base line symptoms and signs of asthma, PFT, amount of rescue medication and nocturnal awakening due to asthma symptoms were recorded and Rotahaler with test medication applied. Statistical analysis was performed on pre and post intervention data.

CONCLUSION: The present study demonstrated that Rotahaler a dry power devise is significantly effective in producing clinical and PFT improvement, in moderate persistent asthma in children.

KEYWORDS: Asthma, Children, Pulmonary Function Test (PFT), Rotahaler, Fluticasone, Salmeterol.

HOW TO CITE THIS ARTICLE: Suddapalli Sivaram Prasad. "Evaluation of Eficacy of Rotahaler with Fluticasone and Salmeterol Medication in Asthmatic Children". Journal of Evolution of Medical and Dental Sciences 2015; Vol. 4, Issue 93, November 19; Page: 15848-15849, DOI: $10.14260 /$ jemds/2015/2298.

INTRODUCTION: This study was conducted to assess the efficacy of Rotahaler with fluticasone and salmeterol in asthmatic children. Clinical, PFT, use of rescue medication and nocturnal awakening due to asthma symptoms was assessed and compared between pre intervention and post intervention.

MATERIALS AND METHODS: This study was conducted in Asthma clinic of the pediatric OPD, at Katuri Medical College and Hospital, Guntur, between 2012 and 2013. A prospective study was planned with 30 patients of both sexes in the age group of 5-12 years, who reported to asthma clinic and fulfilled inclusion and exclusion criteria were included in the study after parental consent. All patients included in the trail were initially entered in to run-in period of 2 weeks, during which a record was maintained of their clinical parameters and allowed to take their prescribed medication.

At the end of run-in period the base line symptoms and signs of asthma, PFT, amount of rescue medication and nocturnal awakening due to asthma symptoms were recorded and Rotahaler with fluticasone 100 micrograms and salmeterol 50 micrograms applied. Various parameters like symptom score (e.g. cough, breathlessness), clinical score (e.g. Wheeze, use of accessory muscles) PFT (e.g. FEV1, FVC, PEFR), nocturnal awakening (e.g. number of nights in week patient awakened due to asthma symptoms as per history), use of rescue medication (Number of salbutamol puffs patient required per week) were used to assess efficacy of device at monthly intervals for two months. Statistical analysis was performed on pre and post intervention data.

Financial or Other, Competing Interest: None.

Submission 29-10-2015, Peer Review 30-10-2015,

Acceptance 10-11-2015, Published 18-11-2015.

Corresponding Author:

Dr. Suddapalli Sivaram Prasad,

Flat No. 4, First Floor, Amrutha Apartments,

Veterinary Colony, Road No. 5,

Vijayawada-5,

Andhra Pradesh, India.

E-mail: suddapalli2000@yahoo.com

DOI:10.14260/jemds/2015/2298.
RESULTS: Of the 30 patient enrolled $27 \%$ were males and $73 \%$ were females. And $30 \%$ of children were in the age group of 5-8.9 years and $70 \%$ of the children were in the age group of 9-12 years age group. Significant improvement (P-Value less than 0.001) was noticed in symptom scores, clinical scores, PFT, nocturnal awakening after $1^{\text {st }}$ and $2^{\text {nd }}$ review and significant improvement in use of rescue medication (P-Value less than 0.01 ) after $1^{\text {st }}$ and $2^{\text {nd }}$ review recorded.

DISCUSSION: In the present day scenario, bronchial asthma is a leading cause of morbidity in our society and more so in pediatric age group. ${ }^{1}$ there have been revolutionary changes in the management of bronchial asthma during past few years. Aerosol therapy has come to stay as the backbone of therapy. Acute attacks in the pediatric age group require hospital management and nebulization is primary mode of drug delivery to the lungs. ${ }^{2}$ whereas inhalation steroids with long acting bronchodilator indicated in moderate persistent and severe persistent asthma.

Our study aimed at evaluation of Rotahaler using drugs fluticasone propionate (100 micrograms) and salmeterol (50 micrograms) in patients of 5-12 age group suffering from moderate persistent asthma. A total of 30 subjects were evaluated, before application of said medication and one month and two months after application of said medication with various disease parameters like symptom score, clinical score, PFT, nocturnal awakening due to asthma symptoms and rescue medication required. Data from baseline, one month after application of medication and two months after application of medication was analyzed.

At the end of one month, there was statistically significant difference between baseline data and first month review data for various parameters like cough, breathlessness, symptom score, wheeze, use of accessory muscles, clinical score, $\mathrm{FEV}_{1}$, FVC, PEFR, nocturnal awakening and use of rescue medication. Moreover, it is true about second review at the end of second review. 
Pieters WR and others from a Netherland based study state both Discus (Accuhaller) and diskhaler proved to be equal in efficacy, safety and were well tolerated. ${ }^{3}$

Rakesh L from AIMS, New Delhi concluded that MDI and dry powder devices are equal in efficacy. ${ }^{4}$ However, Thomus $\mathrm{M}$ and Willium $\mathrm{AE}$ in their study titled 'Are outcomes the same with all dry powder inhalers?' indicate that, different levels of asthma control is possible with different devices even with same chemical entity. ${ }^{5}$

CONCLUSION: The present study demonstrated that Rotacap with combination drugs of fluticasone and salmeterol is significantly effective in improving asthma symptomatology and pulmonary function test results.

\section{BIBLIOGRAPHY:}

1. Vandane Bathra, Sathi GR, Sachdeva HP. Comparative efficacy of jet nebulizer and meter dose inhaler with spacer device in the treatment of acute asthma: Ind Ped $1997 ; 34$.
2. Pederson S. Choice of Inhalation Therapy in Pediatrics: Ero Resp Rev 1994; 4:15-68.

3. Pieters WR, Stallaert RA, Prins J et al. A study on The Clinical Equivalence and Patient Preference of Fluticasone Propeonate $(250$ Micrograms $)$ twice daily via Discus/Accuhaler inhaler or the Diskhaler inhaler in adult asthmatic patients. J Asthma 1998; 35(4):337-45.

4. Rakesh Lodha, Gaurav Gupta, Bedanta Prakash Baruah, Rajiv Nagpal and S.K. Kabra. Metered Dose Inhaler with Spacer versus Dry Powder Inhaler for Delivery of Salbutamol in Acute Exacerbation of Asthma: A Randomized Controlled Trail. Indian Pediatrics 2004; 41:15-20.

5. Thomus M, Willium AE. Are outcomes the same with all dry powder inhalers? Int J Clin Pract Suppl. 2005 Dec ;(149):33-5.

\begin{tabular}{|c|c|c|c|c|c|c|c|c|c|c|}
\hline \multirow{2}{*}{ No. } & \multirow{2}{*}{ VALUE } & \multicolumn{3}{|c|}{ COUGH } & \multicolumn{3}{|c|}{ BREATHLESSNESS } & \multicolumn{3}{|c|}{ SYMPTOM SCORE } \\
\hline & & Base & $1^{\text {st }}$ & $2^{\text {nd }}$ & Base & $1^{\text {st }}$ & $2^{\text {nd }}$ & Base & 1st $^{\text {st }}$ & $2^{\text {nd }}$ \\
\hline 1 & Mean & \multicolumn{3}{|c|}{2.1660 .9000 .366} & \multicolumn{3}{|c|}{2.0000 .2330 .667} & \multicolumn{3}{|c|}{4.1661 .1330 .433} \\
\hline 2 & S.D & \multicolumn{3}{|c|}{0.3790 .4030 .490} & \multicolumn{3}{|c|}{0.0010 .0010 .254} & \multicolumn{3}{|c|}{0.3790 .6290 .626} \\
\hline 3 & S.Err & \multicolumn{3}{|c|}{0.0690 .0000 .089} & \multicolumn{3}{|c|}{0.0000 .0000 .046} & \multicolumn{3}{|c|}{0.0690 .1150 .114} \\
\hline 4 & P-Value & \multicolumn{3}{|c|}{0.0010 .0010 .001} & \multicolumn{3}{|c|}{0.0010 .0010 .001} & \multicolumn{3}{|c|}{0.0010 .0010 .001} \\
\hline 5 & Signi. & \multicolumn{3}{|c|}{ Significant } & \multicolumn{3}{|c|}{ Significant } & \multicolumn{3}{|c|}{ Significant } \\
\hline \multicolumn{11}{|c|}{ Table 1: Comparison of Symptom Score } \\
\hline
\end{tabular}

\begin{tabular}{|c|c|c|c|c|c|c|c|c|c|}
\hline \multirow{2}{*}{ No. } & \multirow{2}{*}{ VALUE } & \multicolumn{2}{|c|}{ WHEEZE } & \multicolumn{3}{|c|}{ USE OF ACCESORY } & \multicolumn{3}{|c|}{ SYMPTOM SCORE } \\
\hline & & Base & $2^{\text {nd }}$ & Base & $1^{\text {st }}$ & $2^{\text {nd }}$ & Base & $1^{\text {st }}$ & $2^{\text {nd }}$ \\
\hline 1 & Mean & \multicolumn{2}{|c|}{2.0330 .2330 .066} & \multicolumn{3}{|c|}{0.2060 .2000 .667} & \multicolumn{3}{|c|}{4.1000 .0430 .100} \\
\hline 2 & S.D & \multicolumn{2}{|c|}{1.1830 .5040 .254} & \multicolumn{3}{|c|}{0.2540 .4070 .254} & \multicolumn{3}{|c|}{0.4030 .7740 .403} \\
\hline 3 & S.Err & \multicolumn{2}{|c|}{0.0330 .0920 .046} & \multicolumn{3}{|c|}{0.0460 .0740 .033} & \multicolumn{3}{|c|}{0.0740 .1410 .074} \\
\hline 4 & P-Value & \multicolumn{2}{|c|}{0.0010 .0010 .001} & \multicolumn{3}{|c|}{0.0010 .0010 .001} & \multicolumn{3}{|c|}{0.0010 .0010 .001} \\
\hline 5 & Signi. & \multicolumn{2}{|c|}{ Significant } & \multicolumn{3}{|c|}{ Significant } & \multicolumn{3}{|c|}{ Significant } \\
\hline \multicolumn{10}{|c|}{ son of Clinical Scol } \\
\hline
\end{tabular}

\begin{tabular}{|c|c|c|c|c|c|c|c|c|c|}
\hline \multirow{2}{*}{ No. } & \multirow{2}{*}{ VALUE } & \multicolumn{2}{|c|}{ FEV1 } & \multicolumn{3}{|c|}{ FVC } & \multicolumn{3}{|c|}{ PEFR } \\
\hline & & Base & $2^{\text {nd }}$ & Base & $1^{\text {st }}$ & $2^{\text {nd }}$ & Base & $1^{\text {st }}$ & $2^{\text {nd }}$ \\
\hline 1 & Mean & \multicolumn{2}{|c|}{72.5693 .2695 .46} & \multicolumn{3}{|c|}{65.6684 .5687 .03} & \multicolumn{3}{|c|}{70.5691 .7695 .80} \\
\hline 2 & S.D & \multicolumn{2}{|c|}{11.139 .4477 .464} & \multicolumn{3}{|c|}{10.559 .1719 .590} & \multicolumn{3}{|c|}{7.74513 .7211 .74} \\
\hline 3 & S.Err & \multicolumn{2}{|c|}{2.0321 .7251 .363} & \multicolumn{3}{|c|}{1.9271 .6741 .751} & \multicolumn{3}{|c|}{1.4142 .5062 .144} \\
\hline 4 & P-Value & \multicolumn{2}{|c|}{0.0010 .0010 .001} & \multicolumn{3}{|c|}{0.0010 .0010 .001} & \multicolumn{3}{|c|}{0.0010 .0010 .001} \\
\hline 5 & Signi. & \multicolumn{2}{|c|}{ Significant } & \multicolumn{3}{|c|}{ Significant } & \multicolumn{3}{|c|}{ Significant } \\
\hline
\end{tabular}

\begin{tabular}{|c|c|c|c|c|c|c|c|}
\hline \multirow{2}{*}{ No. } & \multirow{2}{*}{ VALUE } & \multicolumn{3}{|c|}{ NOCTURINAL AWAKENING } & \multicolumn{3}{|c|}{ RESCUE MEDICATION } \\
\hline & & Base & $1^{\text {st }}$ & $2^{\text {nd }}$ & Base & 1st & $2^{\text {nd }}$ \\
\hline 1 & Mean & \multicolumn{3}{|c|}{4.1661 .0670 .300} & \multicolumn{3}{|c|}{2.0000 .2330 .733} \\
\hline 2 & S.D & \multicolumn{3}{|c|}{0.6480 .9070 .651} & \multicolumn{3}{|c|}{0.0010 .0011 .701} \\
\hline 3 & S.Err & \multicolumn{3}{|c|}{0.1180 .1660 .119} & \multicolumn{3}{|c|}{0.0000 .0000 .310} \\
\hline 4 & P-Value & \multicolumn{3}{|c|}{0.0010 .0010 .001} & \multicolumn{3}{|c|}{0.0010 .0010 .01} \\
\hline 5 & Signi. & \multicolumn{3}{|c|}{ Significant } & \multicolumn{3}{|c|}{ Significant } \\
\hline \multicolumn{8}{|c|}{ Table 4: Comparison of Other Parameters } \\
\hline
\end{tabular}

